\title{
Prediction of Marital Boredom Based on Mindfulness and Comparing These Variables in Couples of Employed Group and Household Group in Ilam City
}

\author{
Somayeh Ali Mohammadi ${ }^{1}$, Mohsen Gol Mohammadian ${ }^{2}$
}

1 Master of Counseling and Guidance, Department of Psychology, Faculty of Literature and Human Sciences, Kermanshah Branch, Islamic Azad University, Kermanshah, Iran.

${ }^{2}$ Assistant Professor in Guidance and Advice Department, Department of guidance and counseling, Faculty of Social Sciences, Kermanshah Branch, Razi University, Kermanshah, Iran.

\begin{tabular}{l} 
ARTICLE INFO \\
\hline Keywords: \\
Marital Boredom \\
Mindfulness \\
Employed \\
Household Group
\end{tabular}

\begin{abstract}
The purpose of this study was to predict marital boredom based on mindfulness and comparing this variable in employed group couples and household group couples in Ilam city. The present study is applied in terms of aim and its implementation method is correlation. The statistical population of the present study is all couples referring to counseling centers in Ilam city during winter 2017, which 248 couples (124 women and 124 men) were selected for inclusion in the study using available sampling method first among all interested parties which has criteria for entry into research 1) at least a diploma degree 2) an age range of 20 to 40 years old 3) have passed at least one year of marriage. The instruments used in this study were marital boredom criterion (Painez 1996) and mindfulness 5-point questionnaire (Baer et al., 2006). Software SPSS 23 was used to analyze study data and finally the results were presented in two sections of descriptive statistics (mean, median, standard deviation) and inferential statistics (T-test of two independent groups, multivariate analysis of variance, Pearson correlation coefficient, and multivariate regression coefficient). The results showed that there is an inverse and significant relationship between marital boredom variables and mindfulness at $95 \%$ confidence level. Also, in the second hypothesis, the mean of three elements of mindfulness between couples in two groups of employed and household is significant. According to the results, it is seen that the mean of three components scores in employed group couples is higher than that of the household group. Also, other results of the study showed that the average marital boredom in household group couples is higher than that of employed group couples. Therefore, the variable of mindfulness is predictive of couples` marital boredom.
\end{abstract}

\section{Introduction}

Family is one of the main pillars of the community. Achieving a healthy community obviously depends on the health of the family, and the realization of a healthy family is conditional on good

* Corresponding Author E-Mail Address: Alireza.samane6059@gmail.com 
relationship among its individuals. In such a system, people are joined together with long-term and mutual interactions. These attachments, although their unity may diminish over time, they will endure throughout family life (Goldenberg, quoted by Hussein Shahi and Naghshbandi, 2004). Marriage is always acknowledged as the most important and highest social standard for meeting the adult's emotional and security needs. Marriage is a delicate and dynamic complex human relationship that has certain characteristics. Also, attention to the family center with a healthy and constructive environment and warm relationships and interpersonal and intimate interactions that can lead to the growth and development of individuals are among the goals and needs of marriage (Barnstein \& barnstein, 1989). Marriage is considered the most exciting and the most stressful event for every human being. By marriage, people show that they are moving forward in the process of their growth. Satisfaction life is one of the prerequisites for the attainment of peace and human evolution (Amanollah et al, 2012).

The upward trend in the statistics of divorce and the existence of conflicts and disturbances in couples' relationships have raised the incentive for researchers to find effective factors and solutions to deal with this collapse of relationships. One of these disturbances and psychological features that over time diminish love and affection among couples and sometimes fades it completely, and causing mental and psychological problems, continuing cold relationships and indifference (emotional divorce) and formal divorce, is marital boredom (Paines, 2007, quoted by Abbasi Esfajir et al., 2016).

The concept of marital boredom is not a static concept, and most couples in their common life experience minor changes in satisfaction level, and as a result they are constantly forced to actively adapt themselves to various aspects of their physical, social and psychological environment (Cumming, and Oreilly, 1997; quoted by Kamayi and Sedaghati Fard, 2015).

Boredom consists of physical, psychological and emotional founder resulting from disagreement between expectations and realities. Boredom with signs of physical founder have symptoms such as feeling tired, boredom, lethargy, chronic headaches, abdominal pain, low appetite, and overeating. An emotional founder is characterized by symptoms such as anxiety, unwillingness to solve problems despair, sadness, feeling empty, meaningless, depression, feeling loneliness, feeling indifferent, trapping, futility, emotional distress, and even suicidal thoughts (Adib Rad, 2006).

In addition to marital boredom, a new structure that has attracted the attention of many researchers is mindfulness. Mindfulness consists of a transient and non-judgmental sense of what is happening now (Ryan and Brown, 2003). Mindfulness people understand the inner and outer realities freely and without distortion and they are so able to deal with a wide range of thoughts, emotions, and experiences both pleasant and unpleasant (Brown et al, 2007).

Mindfulness factors include observation, description, acting with awareness, non-judging, and lack of response to internal experiences (Baer et al, 2006).

Kabat-Zinn (2003) defined mindfulness as paying attention to a specific, purposeful way in the present time and without judgment and prejudice (quoted by Segal et al., 2002). Mindfulness is also effective in the development of relationships between couples. Although research on the effect of mindfulness on marital satisfaction is very low, these few studies show that the factor of mindfulness is effective on marital satisfaction, for example Burpee and Langer, 2005, in a study conducted on 95 people; show that there is a strong correlation between marital satisfaction and mindfulness. They showed that mindfulness is a very effective and efficient way to restore calm at the height of tension, treatments of chronic mental disorders, stress relief and depression and it is extraordinary effective in the development of creativity, memory enhancement, flexibility of 
mind and IQ. When couples have conflict, many couples adopt negative reaction patterns that only exacerbate the conflict, it means instead of finding a two-way solution, they more intend to blame each other. The mindfulness person is less likely to have irrational attitudes and it is more likely that to consider his/her spouse`s point of view. Also, Rajabi and Sotoudeh (2011) findings based on this that the education of mindfulness increases marital satisfaction is consistent with results of Burpee and Langer (2005). And also, researches of Yousefi and Sohrabi (2011) showed that the education of family therapy based on presence of the mind improve the quality of marital relationship and cold-tempered women (Nabavi Hesar and Ahmadi, 2012). Thus, increasing the number of couples in trouble, breaking the balance of families, disrupting of couples' relationships, and also increasing divorce rate in recent years has been a concern for all sociologists and psychologists. Psychological studies in couples show that less than half of them reaching a degree of satisfaction (Gattis et al. 2004). Also, marital satisfaction level is progressively decreased since the mid-1970s. It is important to discover the factors that significantly affect marital satisfaction and prevent dissatisfaction with marriage, separation and divorce (Bradbury et al, 2000). Also, women's employment, despite the improvement of household economic conditions due to the lack of hours of woman attendance in house causes developments in the management and role of family members. Often in families that woman works, men are more involved in work at home, and the husband and wife come to the understanding in many issues, and the positive effects of this behavior is seen on other members of the family, but nonetheless, unfortunately, a percentage of men still consider that household and parenting is the main occupation of woman and although they are aware of the impact of their wives` work and income on solving the bottlenecks in material life, expecting them to do all the work alone on their own. This increasing pressure on doing two responsibilities sometimes makes employed women physical and mental discomfort, depression and frustration, and perhaps it is safe to say that one of the reasons for the dissatisfaction and frustration of employed women in marital life is this issue (Nasaji, 2006). In most of today's marriages, both husband and wife work out-of-home. The consequence of this progress is very important. In such a situation, the husband and wife may be drawn in different directions and inevitably pursue different purposes. As a result, the length of time they are together decreases and their mental strain and external resources increase, as time passed, the husband and wife become more separated (translation from Poor Abadi, 2001). Contradiction in marital relationships arises when couples have different degrees of independence and solidarity in collaborative and cooperative decisions (Callian, 2009). Disagreements and misunderstandings in the family are common and no family is excluded, but sometimes they lead to intense conflict. On this basis, the purpose of the present study is to predict marital boredom based on mindfulness and comparing this variable in couples in Ilam city.

\section{Research Hypotheses}

First hypothesis: There is a relationship between mindfulness and marital boredom in couples. Second hypothesis: There is a difference between mindfulness in couples with an employed woman (employed group) with couples in which woman is household (household group).

Hypothesis (prediction): Mindfulness can predict marital boredom in couples.

\section{Methodology}

The method of this research is applied and its implementation is descriptive of correlation type. The statistical population of this study is all couples referring to Ilam city counseling centers during winter 2017. 248 couples (124 women and 124 men) were selected for inclusion in the study using 
available sampling method first among all interested parties which has criteria for entry into research 1) at least a diploma degree 2) an age range of 20 to 40 years old 3) have passed at least one year of marriage. In this study, the predictive variable is mindfulness and criterion variable is marital boredom.

\section{And Research Instruments Include}

1. Marital boredom scale: marital boredom scale is a self-report instrument developed by Paynes in 1996 with three components of mental and emotional founder and physical founder. The subscale of physical founder has 6 questions, the mental founder subscale has 7 questions and the subscale of emotional founder has 8 questions. This questionnaire consists of 21 items that are symptom of boredom, 17 of which contain negative phrases and 4 of them contain positive statements. Scoring this scale in a 7-degree Likert ranges from 1 (never) to 7 (always). Scoring 4 items is also reversed, and the higher score of the subject on this scale is a sign of more boredom. The maximum total score of the questionnaire is 147 and its minimum is 21 (Painez, 1996; translated by Fatemeh Shadab, 2002). The reliability coefficient of this scale was calculated as 0.76 in a one-month trial with a rehearsal method. Also, the reliability of this scale was calculated using the Cronbach's alpha method in the range of 0.91 to 0.93 (Painez, 1996, Shadab translation, 2002). To assess the validity of this scale, the Enrich marital satisfaction questionnaire was used that correlation coefficient between these two questionnaires was obtained -0.40 , which is significant at the level of $\mathrm{p}<0.001$ (Mollazadeh, 2010).

2- 5-point mindfulness questionnaire of Baer et al,: self-assessment scale has 39 items that is developed through Baer et al. (2006) by combining items from the Freiberg Mindfulness Inventory (FMI) (Walsh et al., 2006), the mindfulness, awareness, and attention scale (MAAS); (Ryan and Brown, 2003), Kanchuki mindfulness scale (KIMS) (Baer and Smiet, 2004); and FFMQ Mindfulness Questionnaire (Baer et al., 2006), using an evolved factor analysis. Reliability and validity of the questionnaire: Based on the results, the internal consistency of the factors was appropriate. The alpha coefficient was in the range of 0.75 (non-reactivity factor) to 0.91 (in description factor). The correlation between factors was moderate and in all cases significant and it is in the range between 0.15 and 0.34 (Neoser, 2010; quoted from Ahmadvand, 2012). Also, in a study on validation and reliability of this questionnaire in Iran, the test-retest correlation coefficients of the FFMQ questionnaire was observed as $r=57$ (related to non-judgmental factor) and $r=0.84$ (observation factor) in the Iranian sample. Also, Alpha coefficients were also found to be acceptable (between $\alpha=0.55$ related to non-reactive factor and $\alpha=0 / 83$ related to the description factor) (Ahmadvand, 2012).

\section{Data Analysis Method}

For analyzing study data, the software version SPSS 23 was used. Finally, the results were analyzed in two frames of descriptive statistics (mean, median, standard deviation) and inferential statistics (T-test of two independent groups, multivariate analysis of variance, Pearson correlation coefficient and multivariate regression).

Findings:

Descriptive indexes of research variables:

This section is prepared in two parts, according to the research purpose and in accordance with the statistical hypothesis. In the descriptive section, data are adjusted in a table and descriptive indexes such as mean and standard deviations of main research variables are presented and reviewed. Then, 
in the inferential part, the research hypotheses are investigated by analyzing data and the use of statistical methods such as T-test of two independent groups, multivariate analysis of variance, Pearson correlation coefficient and multivariate regression. The number of credible samples for doing the necessary analyzes was equal to 62 couples who were male and employed female (employed group) and 62 couples that consists of employed men and housewives (household group).

Table 1: descriptive indexes and investigating normality of components and total score of mindfulness

\begin{tabular}{|l|l|c|c|c|c|c|}
\hline \multicolumn{1}{|c|}{ Variable } & \multicolumn{1}{|c|}{ Group } & Number & Mean & $\begin{array}{c}\text { Standard } \\
\text { deviation }\end{array}$ & K-S & Significance \\
\hline \multirow{2}{*}{ Observation } & Employed & 124 & 30.46 & 4.853 & 1.146 & 0.144 \\
\cline { 2 - 7 } & Household & 124 & 31.70 & 4.414 & 1.138 & 0.165 \\
\hline \multirow{2}{*}{ Description } & Employed & 124 & 23.71 & 3.724 & 1.092 & 0.187 \\
\cline { 2 - 7 } & Household & 124 & 23.65 & 2.699 & 1.018 & 0.251 \\
\hline \multirow{2}{*}{ Action with awareness } & Employed & 124 & 26.35 & 6.316 & 1.049 & 0.205 \\
\cline { 2 - 7 } & Household & 124 & 22.55 & 6.036 & 1.168 & 0.128 \\
\hline \multirow{2}{*}{ Non-judgment } & Employed & 124 & 21.34 & 4.691 & 1.159 & 0.134 \\
\cline { 2 - 7 } & Household & 124 & 21.12 & 4.956 & 1.107 & 0.183 \\
\hline \multirow{2}{*}{ Total score of mindfulness } & Employed & 124 & 22.38 & 3.606 & 1.243 & 0.091 \\
\cline { 2 - 7 } & Household & 124 & 23.94 & 3.644 & 1.026 & 0.243 \\
\cline { 2 - 7 } & Employed & 124 & 124.23 & 13.124 & 1.085 & 0.191 \\
\cline { 2 - 7 } & Household & 124 & 122.96 & 9.850 & 1.019 & 0.250 \\
\hline
\end{tabular}

Table 1 show mean and standard deviation of components' scores and total score of mindfulness in two groups of couples who have employed men and women (employed group) and couples who have employed men and housewives (household group). The mean and standard deviation of the total score of mindfulness for employed group were 12.23 and 134. 124, respectively; and it was obtained 12.96 and 9.850 for housewives, respectively. Also, in table 1, the normalization of components data and total score of mindfulness are shown. According to the results, Kolmogorov-Smirnov statistics values for all variables are small and the corresponding significant values are greater than 0.05 . Therefore, the data values of the variables follow the normal distribution.

\section{Inferential data}

First Hypothesis: There is a relationship between mindfulness and marital boredom in couples. Table 2: Correlation coefficient between sexual intimacies with dimensions of mindfulness

\begin{tabular}{|c|l|c|c|c|c|c|c|}
\hline & Observation & Description & $\begin{array}{c}\text { Action with } \\
\text { awareness }\end{array}$ & $\begin{array}{c}\text { Non- } \\
\text { judgment }\end{array}$ & $\begin{array}{c}\text { No } \\
\text { reaction }\end{array}$ & Mindfulness \\
\hline \multirow{2}{*}{$\begin{array}{c}\text { Marital } \\
\text { boredom }\end{array}$} & $\begin{array}{l}\text { Pierson } \\
\text { correlation }\end{array}$ & 0.063 & -0.160 & -0.501 & -0.358 & 0.074 & -0.427 \\
\cline { 2 - 8 } & $\begin{array}{l}\text { coefficient } \\
\text { significance }\end{array}$ & 0.325 & 0.012 & 0.001 & 0.001 & 0.243 & 0.001 \\
\hline
\end{tabular}


Table 2 shows the correlation between marital boredom with dimensions of mindfulness. It can be seen that the values of Pearson correlation coefficient between marital boredom with dimensions of description, action with awareness, non-judgment, and total score of mindfulness were -0.160 , $-0.501,-0.385$, and -0.427 , respectively that are meaningful at level of $\mathrm{P}<0.05$, therefore, the zero hypothesis is rejected and research hypothesis based on the relation between marital boredom with dimensions of mindfulness is accepted. Thus, there is a reverse and significant relationship between marital boredom and mindfulness variables in the $95 \%$ confidence level. Given that they range from 0.35 to 0.65 , their severity is moderate.

Second hypothesis: There is a difference between mindfulness in couples with an employed woman (employed group) and couples with housewives (household group).

Table 3: Levin test of scores variance homogeneity of mindfulness dimensions in two groups of employed wives and housewives

\begin{tabular}{|l|c|c|c|c|}
\hline \multicolumn{1}{|c|}{ Subscale } & F & Freedom degree 1 & Freedom degree 2 & Significance level \\
\hline Observation & 2.571 & 1 & 246 & 0.110 \\
\hline Description & 2.411 & 1 & 246 & 0.124 \\
\hline Action with awareness & 0.438 & 1 & 246 & 0.509 \\
\hline Non-judgment & 0.337 & 1 & 246 & 0.562 \\
\hline No reaction & 2.639 & 1 & 246 & 0.106 \\
\hline
\end{tabular}

Table 3 showed the results of Levin homogeneity test for the variance of mindfulness dimensions error scores in two groups of employed and housewife groups; significant level obtained for $\mathrm{F}=2.571, \mathrm{~F}=2.411, \mathrm{~F}=0.438, \mathrm{~F}=0.337$, and $\mathrm{F}=2.639$ is greater than 0.05 , so default of homogeneity of variance variables is confirmed.

Table 4: Multivariate variance analysis of comparing mean scores of mindfulness components in two groups of employed and housewives

\begin{tabular}{|c|l|c|c|c|c|c|}
\hline $\begin{array}{c}\text { Changes } \\
\text { source }\end{array}$ & Coefficient & Value & $\mathrm{F}$ & $\begin{array}{c}\text { Freedom degree } \\
\text { of hypothesis }\end{array}$ & $\begin{array}{c}\text { Error freedom } \\
\text { degree }\end{array}$ & Significant \\
\hline \multirow{4}{*}{ Group } & Pillaie`s trace & 0.197 & 11.839 & 5.00 & 242.0 & 0.001 \\
\cline { 2 - 7 } & Landai Wikile & 0.803 & 11.839 & 5.00 & 242.0 & 0.001 \\
\cline { 2 - 7 } & Hoteling effect & 0.245 & 11.839 & 5.00 & 242.0 & 0.001 \\
\cline { 2 - 7 } & The largest root & 0.245 & 11.839 & 5.00 & 242.0 & 0.001 \\
\hline
\end{tabular}

Table 4 shows the significance of independent variable effect of the group (employed or housewife) on five components of mindfulness among couples in both employed and housewives groups. As it can be sees, all four tests of Pillaie, Landai Wikile, Hoteling effect and the largest Root are significant on the level of $\mathrm{P}<0.01$ and it is concluded that the independent variable of the group is at least affect significantly on one of the five components of observation, description, action with awareness, non-judgment and lack of reaction. 
Table 5: tests of effects among subjects in comparing means of mindfulness components in two groups of employed and household

\begin{tabular}{|c|l|c|c|c|c|c|}
\hline $\begin{array}{c}\text { Changes } \\
\text { source }\end{array}$ & \multicolumn{1}{|c|}{ Dependent variable } & $\begin{array}{c}\text { Sum of } \\
\text { squares }\end{array}$ & $\begin{array}{c}\text { Degree of } \\
\text { freedom }\end{array}$ & $\begin{array}{c}\text { Average of } \\
\text { squares }\end{array}$ & F & Significant \\
\hline \multirow{5}{*}{ Group } & Observation & 95.629 & 1 & 95.629 & 4.445 & 0.036 \\
\cline { 2 - 7 } & Description & 0.198 & 1 & 0.198 & 0.019 & 0.891 \\
\cline { 2 - 7 } & Action with awareness & 894.520 & 1 & 894.520 & 23.443 & 0.001 \\
\cline { 2 - 7 } & Non-judgment & 2.940 & 1 & 2.940 & 0.120 & 0.730 \\
\cline { 2 - 7 } & No reaction & 150.198 & 1 & 150.198 & 11.430 & 0.001 \\
\hline
\end{tabular}

Table 5 shows the results of significant or non-significant effects between subjects in comparison with the mean scores of five components of mindfulness. As it is seen in the source of the group changes, the values of $\mathrm{F}$ are obtained for three components of observation, the action with awareness and non-reaction as 4.454, 23.443 and 11.430, respectively, and they are significant at $\mathrm{P}<0.01$. Therefore, hypothesis zero is rejected and research hypothesis based on the significant difference between the mean of three components of mindfulness between couples of employed and housewives is significant. According to table 5, it is seen that mean scores of three components in employed group couples is higher than that in the housewife group couples.

Hypothesis (prediction): Mindfulness can predict marital boredom in couples.

Table 6: prediction of marital boredom by mindfulness

\begin{tabular}{|l|c|c|c|c|c|c|c|c|}
\hline & \multicolumn{1}{|l}{ Model } \\
\hline & $\mathrm{B}$ & $\mathrm{SE}$ & $\beta$ & $\mathrm{t}$ & $\mathrm{P}$ & $\mathrm{R}$ & $\mathrm{R}^{2}$ & $\mathrm{~F}$ \\
\hline Marital boredom & & & & & 0.001 & 0.631 & 0.398 & 53.738 \\
\hline Model constant & & 185.933 & 10.870 & & 17.106 & 0.001 & & \\
\hline Mindfulness & & -0.263 & 0.094 & -0.170 & -2.792 & 0.006 & & \\
\hline
\end{tabular}

Table 6 shows the prediction of marital boredom by mindfulness in couples. The results of multiple linear regression analysis showed that multiple linear regression coefficient for marital boredom and predictive variable are significant. As it is shown in table 6, for each unit increase in standard deviation of mindfulness scores, marital boredom scores of couples were decreased to 0.170 of standard deviation.

\section{Discussion and conclusion}

The present research aims to answer to the question of whether mindfulness can predict marital boredom in couples. Based on the results of the research, the relationship between mindfulness and marital boredom in couples is accepted, and there is a reverse and significant relationship between variables of marital boredom and mindfulness at the $95 \%$ confidence level, but their intensity is moderate. Consistent with the results of this research and in the study of findings in the field of mindfulness, although research on the effect of mindfulness on marital satisfaction is very low, these few studies show that the factor of mindfulness is effective on marital satisfaction. Halestin (1993) defines a framework for the boredom process. He defines boredom as a form of depression that results from a founder process. Some research suggests that boredom grows within depression under certain conditions (Quoted from Mousavi Zadeh, 2009). Biker (2009) in his 
research showed that different behaviors of boredom with mental health and marital boredom are significantly related with depression. Since some of boredom symptoms, such as sadness, pessimism and feeling guilt (Tabatabaei, 2003) are common to depression, the findings of this research can be consistent with research of Tezel et al., 2000; Maan and Tezdel, 2004; Evans et al., 2008; Yoondolfi et al., 2010; Azarghon et al. 2009; Narimani et al. 2011; Mohammad Khani et al. 2011; and Mottahari et al. 2012 based on effectiveness of mindfulness approach in reducing depression. Also, for example, Burpee and Langer (2005), in a study conducted on 95 people, showed that there is a strong correlation between marital satisfaction and mindfulness. They showed that mindfulness is a very effective and efficient way to restore calm at the height of tension, to treat chronic mental disorders, to relieve stress, and depression, and it has an extraordinary effect on creativity, memory enhancement, mind flexibility, and IQ. When couples have conflict, many couples display negative reaction patterns that only exacerbate the main conflict, which means instead of finding a mutual solution they are more likely to blame each other. A mindfulness person is less likely to have irrational attitudes and he/she is more likely to consider his wife's point of view. Also, findings of Rajabi and Sotoudeh (2011) based on increasing marital satisfaction by mindfulness education are consistent with the results of Burpee and Langer (2005). And also, research of Yousefi and Sohrabi (2011) showed that family-therapy education based on presence of the mind improves the quality of women's marriages and cold-temper (Nabavi Hesar and Ahmadi, 2012). Hence, increasing the number of couples in trouble, breaking the balance of families, disrupting couples relationships, and increasing the divorce rate in recent years has raised concerns of all experts in sociology and psychology. Psychological studies in couples show that less than half of them are in satisfaction (Gattis et al., 2004). Also, marital satisfaction level is progressively decreased since the mid-1970s. The discovery of factors that significantly affect marital satisfaction and prevent dissatisfaction with marriage, separation and divorce is important (Bradbury et al., 2000). Conflict in marital relationships arises when couples have different degrees of independence and solidarity in collaborative and joint decisions (Callian, 2009). Differences and disagreements in the family are commonplace and no family is excluded, but sometimes it leads to extreme conflicts. Today, families are confronted with a variety of conflicts and extreme disagreements which cause the poor and healthy functioning of the family as the first and oldest social institution. An institution whose main function is to create a healthy personality became a factor for emotional, behavioral, and personality disputes (Abdullahi, 2005; quoted by Sadaghpour and Hojjatkhah, 2015). Mindfulness with the help of breathing and using body members of awareness of events, awareness of body, breathing, sound and thoughts, and the acceptance of opinions without judgment about them leads to change in certain emotional meanings, and a person realizes that thoughts are simple before reflecting reality, and these negative and anxious thoughts are not necessarily correct. Mindfulness method allows one to realize his automatic activities and normal behaviors, and he/she gain high awareness and consciousness in his/her daily activities; this awareness of thoughts and feelings leads to a change in the relationship of that person with those thoughts and feelings. In fact, mindfulness instead of changing the content of thoughts, changes the relationship of the person with his thoughts. Once a person can achieve this skill, he can be aware of the problems and obstacles and find the right solutions, and according to Burpee and Langer 2005, a conceptual arrangement for couples is created, enabling them to evaluate and reevaluate their common life and problems (quoted by Yousefi and Ozrabi, 2011). This can have a significant effect on the reduction of couples` marital boredom. Thus, according to the results of this research hypothesis, we can say that mindfulness can predict marital boredom in couples. 
Second hypothesis: There is a difference between mindfulness in couples with an employed wife (employed group) and couples with housewives (household group). The results of the study showed that the mean of three components of mindfulness was significant between two groups of employed and housewife. According to the results, the mean scores of three components in the couples of employed group were higher than that of the housewife group. Also, consistent with the results of this study, Hosseini and Khajoui Zadeh (1395), in a research aimed at the relationship between mindfulness and marital satisfaction in married women and men working in the welfare management of Kurdistan province in 2015, using the Cochran formula, 66 people were sampled and they were selected by census method. Results of the research showed that there is a positive and directly meaningful relationship between mindfulness of married employees and their marital satisfaction. Also, Muntazir Maqbool Kermane (2016), in a research aimed at a psychological study of stress among female employees and housewives, and its management through progressed relaxation technique (PMRT) and Mental Respiratory, showed that the level of stress in female employees is higher than that of housekeepers one. The wives of the intervention sessions of Progressed Muscle Relaxation Technique (PMRT) and mindfulness breathing were presented to the experimental group of 25 female employees and no intervention was given to 25 other workers. Women in control group after the post-test intervention was 23778.77 meaningful at 0.05 in experimental group and $t=1.685$ in the control group were significantly 0.05 and 0.01 . This significant reduction in stress level in the experimental group of employed women is determined and without decreasing, the control group reduces the stress level from moderate to low stress levels. In explaining the results of this hypothesis we can say that special attention to women and their role in society is inevitable. So, one of the biggest developments in the last century is dramatic increase of women participation in social and economic, and finally, various areas. Women are important factors in the development of each country. As women in developed countries play an important role in social and economic development. Statistical evidence from developing countries shows that women's participation in jobs related to education, nursing and services is higher (Nasrkhani et al., 2012; quoted by Naghibi et al 2017). The findings also show that employment increases psychological well-being and quality of life of women. Thus, we can tell the community that the employment and socialization of human nature contributes to the development of humanity and the mindfulness of people and especially couples, and also it does not cause separation, depression and boredom of couples.

\section{Research suggestions}

It is suggested that similar research carried out in other societies, since increasing the scope of such research can prevent many family problems and psychological and social harm, and it is better to use questionnaires in similar researches with less questions in order to allow respondents to respond with more patience. It is suggested that this research is repeated in other regions and other age groups for more generalizations of the findings.

Other examples with different variables such as higher education, in different cities, with variables such as depression, happiness, etc., should be reviewed. Applied research proposals include:

- Helping family counselors and therapists of couple to understand the causes of marital satisfaction and better solving marital problems in this way and maintaining the marital relationship of couples.

- Achieving a satisfactory marital life requires a number of features, including the ability to trust and collaborate with others. 
- Identifying the dimensions of couples' intimacy and attempt to reduce marital boredom through education, counseling and other health interventions.

- Identifying the variables related to mindfulness and marital boredom and attempt to promote these variables in order to increase the level of mindfulness components and reducing marital boredom in a space with calmness and trust.

- As employed women as well as men who have employed women have high marital satisfaction, due attention should be paid to this conflict and the causes of this issue should be addressed.

- Given the ever-increasing changes in society and the increase in women's employment, it is better for men and women to be trained to better understand their spouse's moral qualities and understand each other's mental conditions.

- Teaching couples in counseling centers that women's employment not only cause problems for families, but also helps marital satisfaction and marital boredom reduction.

- Decreased and lack of marital satisfaction and increased marital boredom is one of the most important reasons for couples' referrals to family counselors and therapists. The rising rate of divorce and even the advance of divorce rates compared to marriage and the existence of conflicts and disturbances in couples' relationships increased the incentive for scholars to find suitable solutions to confront this social phenomenon. Several studies have shown that unsustainable and unrelenting marriages, in addition to increasing psychological and physical problems in the husband and wife, it also increases these problems in their offspring.

- Based on the assessment of marital boredom, therapists can plan an appropriate program for helping couples exposed to boredom. Considering the confirmation of research hypotheses, especially the role of women's employment in reducing marital boredom, we can use the results of this research to improve the process of couple therapy and preventing the process of boredom between couples.

\section{Acknowledgment:}

Authors thank the sincerest cooperation of all counselors in Ilam city counseling centers and all couples participating in this research.

\section{References:}

Abbasi Esfjir, Ali Asghar, Ramezani, Lida and Javanmard, Mehdi (2016). Reviewing relationship between family function and marital satisfaction with marital boredom of married teachers in Behshahr city. The Expert-Scientific Quarterly of discipline knowledge of Mazandaran province, seventh year, number four (series 27), Winter, 2016, pp. 51-70.

Abdullahi, A. (2015). Marital Conflicts, Sepand Magazine, 35 (5).

Arefi, Mokhtar, Navabinejad, Shokoh, Abdollah, Shafiabadi and Kiyamanesh, Alireza (2014). Attachment styles, gender, marital satisfaction. Psychological research. No. 3. Vol.16.

Bernard, D. H. A. (1998), Residue of tradition :jobs, careers, and spouses time in house. journal of marriage and the family; 49, 281-390.

Bowans, H .A . \& Ipecoch, s. (2005), A marriage for moderns. NewYork: McGraw Hill.

Bradbury TN, Fincham FD, Beach SRH. Research on the nature and determinants of marital satisfaction: A decade in review. Journal of marriage and the family 2000; 62: 964-80.

Brown KW, Ryan RM. The benefits of being present: Mindfulness and its role in psychological well-being. J Pers Psycho 2003 Apr., 84(4): 822-48.

Callian, T. \&Siewgeok, L. (2009).Astudy of marital conflict on measuresonsocial support and mental healt.sunway university collage. 
Coltrane, s. (2000), Research on house hold Labor: Modeling and measuring the social embedness of routine family work. Journal of marriage and the family; vol:62, pp. 208-260.

Ebadatpour, Behnaz, Nawabi Nejad, Shokouh, Shafi Abadi, Abdollah, Falsafinejad, Mohammad Reza (2013). The Mediating Role of Family Functions for Individual Resilience and Spiritual Beliefs and Marital Boredom, Methods and Psychological Models, Year 3, No. 13, Pages 2945.

Epstein, N,. Baldwin, L,.\& Bishop, D. (1983). The McMaster family assessment device.

Franklin, N. B \& Haferbray, B, (2000). Reacting out in family therapy. New.

Gottman, J. M. (1994). A theory of marital dissolution \& stability.Journal of family psychology.1, 547-557.

Heejeong, C. Nadine, F. (2008). Marital conflict, depressive symptoms andfunctional impairment. Journal of Marriage and Family. 2, pp. 377-390.

Hurtung, p. j, \& Rogers, j.R (2000), Work -family commitment and attitudes toward.

Ismaiel Beigi, Zohreh and Gholamrezaei, Hamid Reza (2009); "Intimacy Miracle, Key to Life and Successful Relationship"; Tehran: Noandish publication.

Journal OfMarital And Family Therapy, 9: 171-180.

Kayser, K. (1993). When love dies: Theprocess of marital disaffection. NY:Guilford.

Keitner, G. I. ,Kyan, C. , Miller, I. W. , Bishop, D. S. , Epstin, N. B. (1991). A crosscultural study of major depression \& family functioning.Canadian journal of psychiatry. 36 (4), 254-259.

Khasie, L (2013). The meaning of spouses' privacy in successful marriages (marriage privacy and boundaries in the face of a factor or a third person). Tehran: Ghatre Publishing.

Kolik, (2001), The impact of men's and women's retirement on marital relationship a comparative analysis . journal of women aging; vol:13, No:2, p:21-37.

Kolik, L. Martial, (2001), Power relation's, resource and gender role Ideology, journal of comparative family studiesvol: 30, No:2, p:189-206.

Laaya Sadat Naghibi\&, Saeid Moutavalli,\& Saeid Moutavalli \&Saeid Moutavalli (2017).Compare Mindfulness, zero Psychological Well-Being and Quality of Life between Working Women and Housewives District 6 Area of

Likcani, A. (2013). Differentiation andintimate partner violence. Dissertation for Doctor of Philosophy, College of HumanEcology, Kansas State University.

Mani,(2004), Brief report social self concept of educated unemployed women. Journal of social psychiatry; vol.44, pp.71-74.

Mazzarantani, J. (2011). The divorce survivalguide: What you need to know to protectyour emotional and financial security.Miami: Jules Mazzarantani PLLC.

Miller, L. W. Ryan, C. E. , Keitner, G. L. , Bishop, D. S. , \&Epstin, N. B. (2000). The McMaster approach to family: theory, assessment, treatment \& research.Journal of family. 22, pp. 168189.

Mohammadi Mazidi, Hadi (2014). Relationship between family function and self-control with marital boredom in couples. Master's thesis, Islamic Azad University, Marvdasht Branch Faculty of Educational Sciences and Psychology.

Naderi, Farah; Azammanesh, Pooneh (2012). Comparison of marital boredom, family function and intimacy of male and female employees. New findings in psychology, year 7, no. 22, pp. 97-112.

Nasaji, Z. (2006). W omen, employed, family, AfarineshMagazine , 235 \{inpersion\} 
Navidi, Fatemeh (2005). Study and comparing relationship between marital boredom and organizational climate factors in the staff of hospitals 'nurses' education departments in Tehran. Master's degree in counseling major and family attitude, Shahid Beheshti University.

Nazari, Ali Mohammad (2007). Basics of Couple Therapy and Family Therapy. Tehran: Elm Publications.

Neils,H.(2015).13 sings of burnout and how to help you avoid it. Http:// suu.edu/facalty/gubl. Retrived in 15 Aug. 2015.

Nejad naderi, S., Darehkordia., Divsalar, K. (2013). The study of adjustment changes after teaching of transactional analysis (TA) to the people. IOSR Journal of Humanities and Social Science (IOSRJHSS), 10, pp.31-34.

Owen, B. \& Orther, J. 1983, Sex role congruency \& marital quality, Journal of Marriage \& Family, $\mathrm{N}: 45(1)$, PP: 33-46.

Pantea, Jahangir (2012). Comparison of family performance and marital satisfaction in employed and non-employed (household) married women in Tehran. Quarterly Journal of Educational Management Research, Vol. 3, No. 4 (12), Pages 177-192.

Parcover, J. A., Mettrick, J zero., Parcover, C. A. D., \& Griffin-Smith, P. (2011),University and college counselors as athletic team consultancy: using a structural family therapy model. Journal of College Counseling, 12(2), pp. 149-161.

Paynes, Ayala Malach (1996). Boredom for marital relations, translated by Habib Gohari Rad and Kamran Afshar (2005), Tehran: Radmehr. 10-11.

Paynes, Ayala Malach (1996). What can we do that our dream love lead not to boredom, translated by Fatemeh Shadab (2002), Tehran Ghoghnous Publishing.

Pokorska, J., Farrell, A., Evanschitzky, H., \&Pillai, K. (2013). Relationship fading inbusiness-toconsumer context. In S. Sezgin,E. Karaosmanoglu, \& A. B. Elmadag Bas(Eds.), EMAC 2013: 42nd AnnualEuropean Marketing Academy conference:Lost in translation. Istanbul: Turkey.

Sadaty, A., Mehrabi Zadeh Honarmand, M., and Sudani, M. (2014). Reliability, and factor analysis of Kaiser marital boredom scale. First National Congress of Family Psychology, Shahid Chamran University of Ahvaz.

Sadeghpour, Atousa; Hojjatkhah, Mohsen (2015). Comparison of marital conflicts and mental health in employed and non-employed women referring to private clinics in the city of Kangavar, Master's thesis of clinical psychology, Islamic Azad University, Kermanshah Science and Research Branch.

Sokolski, D. M.; Hendrick,ss (1999), Fostering Marital satisfaction.Family Therapy vol.26(1):3949.

Taghvaee, P. (2006). A comparison between familiar \& non familiarmarriage of marital conflict, M.A thesis of Tehran university. \{in persion\}.

Tehran Laaya Sadat Compare Mindfulness, Psychological Well-Being and Quality of Life between Working Women and Housewives District 6 Area of The International Journal of Indian Psychology ISSN 2348-5396 (e) | ISSN: 2349-3429 (p) Volume 4, Issue 3, DIP 18.01.092/2017040 3http://www.ijip.in | April-June, 2017.

Tichenor,V.J. (2003), Status and income as gendered resource : the case of marital power. Journal of marriage and the familyvol: 61,p:638-650.

Toller,A.; Kelley, B. and stebbing, s. (2009), Assertive sexrole stereotyping and self-concept .journal of psychology;93,157-168. 